\title{
Strategy as Truth: respostas estratégicas na gestão de crises após um crime corporativo
}

\section{Strategy as Truth: strategic responses in crisis management after a corporate crime}

\author{
Cintia Rodrigues de Oliveira Medeiros ${ }^{1}$ \\ Rafael Alcadipani ${ }^{2}$
}

\begin{abstract}
Resumo: Neste artigo, analisamos as respostas estratégicas da Chevron durante a gestão de uma crise corporativa provocada por um crime ambiental. O processo de estratégia compreende a busca por uma posição competitiva, e a gestão de crise consiste no gerenciamento de uma situação que ameaça a sobrevivência da empresa. Para abordar a integração da gestão estratégica à de crise, utilizamos a pesquisa documental para a coleta de dados e a análise retórica como técnica de análise. Como resultados, apontamos que as verdades produzidas pela empresa na gestão de crise é resultado da relação entre o discurso e a estratégia.
\end{abstract}

Palavras-chave: Crises corporativas. Crimes corporativos. Discurso e estratégia.

\begin{abstract}
In this paper, the strategic responses of Chevron during the management of a corporate crisis caused by an environmental crime in Rio de Janeiro were analyzed. The strategy process includes the search for a competitive position, and crisis management means dealing with a situation that threatens the survival of the company. In order to analyze the integration of the strategic management with crisis management, a documentary research was carried out for data collection, and a rhetorical analysis was conducted. The results show that the truths revealed by the company in the crisis management result from the relationship between discourse and strategy.
\end{abstract}

Keywords: Corporate crisis. Corporate crimes. Discourse and strategy.

\section{Introdução}

Os estudos de estratégia desenvolveram-se em diversas abordagens, tornando-se foco de interesse de pesquisadores (MINTZBERG; AHLSTRAND; LAMPEL, 2000; HENDRY, 2000; WHITTINGTON, 2002; entre outros) que dirigiram esforços para sistematizar o conhecimento produzido no campo, elaborando análises e propondo categorias conforme sua natureza, influências, processo decisório e outras características. Embora esses autores tenham caminhado por direções diferentes, é comum entre suas propostas a ideia de uma perspectiva da estratégia com orientação normativa e prescritiva quanto ao que fazer para que a empresa obtenha vantagens competitivas e um desempenho superior. Todavia, a despeito da elaboração de um plano estratégico pautado em análises e ferramentas sofisticadas, grandes companhias, frequentemente, se veem envolvidas em uma crise corporativa decorrente de um acontecimento provocado na dinâmica do seu sistema técnico-organizacional-social, como quando ocorre um derramamento de óleo, quando um avião cai, quando uma criança sofre um acidente em brinquedos de um parque de diversões.

Considerando a variedade de conceitos de crises corporativas e a falta de consenso quanto ao significado do termo, adotamos, neste estudo, o conceito de Shaluf, Ahmadun e Said (2003, p. 24), para os quais uma crise consiste em " [...] uma situação na qual decisões importantes envolvendo ameaças ou oportunidades devem ser tomadas em um curto espaço de tempo [...]", podendo ser de origem natural ou provocada pelo homem.

As crises corporativas exercem impactos profundos nas organizações envolvidas, bem como sobre seus públicos mais relevantes. A nossa sociedade tem sentido os efeitos de muitas crises corporativas, das quais poucas são resolvidas, de acordo com analistas, de forma efetiva, satisfatória ou moralmente aceitável. O crime corporativo ambiental, foco deste estudo, desencadeia uma crise corporativa de proporções

\footnotetext{
${ }^{1}$ Área de Organizações e Estratégia, Faculdade de Gestão e Negócios, Universidade Federal de Uberlândia - UFU, CEP 38400-902, Uberlândia, MG, Brasil, e-mail: cintia@fagen.ufu.br

${ }^{2}$ Escola de Administração de Empresas de São Paulo - EAESP, Fundação Getúlio Vargas - FGV, CEP 01313-902, São Paulo, SP, Brasil, e-mail: rafael.alcadipani@fgv.br
} 
inestimáveis, pois provoca reações de governos e da sociedade de modo geral, desempenhando a mídia um papel relevante no processo de gestão de crise, o qual se inicia após o acontecimento. Diante de acusações e denúncias, as corporações agem de diversas formas, com respostas estratégicas, amparadas em uma estrutura retórica, servindo-se de discursos que fabricam verdades sobre a sua atuação.

A corporação como forma de negócios surgiu no século XIX, mais propriamente, sob o sistema institucional-legal norte-americano, quando o sistema de produção artesanal foi suplantado pelo sistema fabril e tornou o modo preferido pelos capitalistas para organizar suas empresas (CLINARD et al., 1979). Nesse contexto, as corporações são acusadas de fixação de preços, exploração, crimes ambientais e outras práticas abusivas, resultando em uma reação política, e o governo, agências reguladoras, especialistas, bem como outros organismos da sociedade civil organizada exercem pressões, de diferentes maneiras, sobre elas.

Com a ocorrência de crises corporativas cada vez mais frequentes e devido ao modo pelo qual as companhias lidam com elas, uma questão permanece sem resposta: de que forma o processo de gestão de crises está integrado com a gestão estratégica? Abordagens alternativas ao mainstream da estratégia apontam para a perspectiva sociológica como capaz de oferecer um corpo teórico metodológico para a compreensão da estratégia a partir das interações sociais. Nessa abordagem, a análise do discurso, como prática social que é, pode contribuir para a compreensão dessa questão.

Neste artigo, analisamos as estratégias de respostas utilizadas pela multinacional Chevron, depois do vazamento no poço de petróleo na plataforma utilizada pela empresa petrolífera norte-americana, na Bacia de Campos/RJ, em novembro de 2011. Esse evento, caracterizado como um crime corporativo ambiental, desencadeou uma crise corporativa diante da qual a companhia utilizou respostas estratégicas para lidar com seus diversos stakeholders, entre os quais o governo, as agências reguladoras e especialistas, focalizados nesta pesquisa.

Ancorados na proposta de Phillips, Sewell e Jaynes (2008) quanto à complementaridade de três abordagens que relacionam o discurso e a estratégia - estratégia como verdade, estratégia como significados compartilhados e estratégia como texto e discurso -, realizamos uma pesquisa documental em reportagens publicadas no jornal Folha de S. Paulo, buscando identificar as reações do governo, agências reguladoras, sociedade civil organizada, especialistas e outros interessados, em relação ao caso. Essa perspectiva no campo da estratégia é recente nos estudos de organizações e estratégia, não havendo, nos estudos nacionais, pesquisas que analisem a estratégia sob a complementaridade dessas três abordagens que a relacionem com o discurso, o que consideramos uma contribuição deste artigo.

Para identificar os elementos que compõem o discurso da empresa nas respostas à crise, e selecionar fragmentos retóricos (REBOUL, 2004), realizamos uma pesquisa documental no website da empresa. Na operacionalização da análise, identificamos, nas respostas estratégicas da empresa, os elementos da estrutura retórica (REBOUL, 2004), quais sejam, o gênero do discurso, o orador, a audiência e os meios de prova, e cruzamos com o tipo de argumentação que esses trazem para o discurso: logos (lógica), pathos (emoção) e ethos (ética).

Apresentamos o artigo estruturado da seguinte forma: inicialmente, discutimos os processos de gestão de crises e gestão estratégica, e os estudos que propõem considerar o discurso na análise e pesquisa em estratégia. Em seguida, descrevemos o modo pelo qual conduzimos a pesquisa, discutimos os resultados e, por fim, encerramos com as considerações finais.

\section{Decisões estratégicas na gestão de crises quando ocorre um crime corporativo}

A gestão de crises e a gestão estratégica, como campos de estudos, desenvolveram-se sem muitas conversações entre si, durante várias décadas, embora estejam intrinsecamente relacionados (MITROFF; PEARSON; PAUCHANT, 1992). O fato de esses dois campos terem se desenvolvido de forma paralela pode ser explicado pela ênfase dada, por parte de consultores, executivos e pesquisadores, às questões relacionadas ao desempenho financeiro e ao crescimento, recebendo as crises pouca atenção (MITROFF; SHRIVASTAVA; UDWADIA, 1987). Porém, desde o início dos anos 1990, quando os escândalos corporativos tomaram maior vulto, e as práticas administrativas questionáveis e ilegais por parte das grandes corporações passaram a fazer parte dos noticiários, com frequência cada vez maior, surgiu, no mesmo compasso, uma crise de desconfiança nas corporações (CHILD, 2002).

Nesse cenário, as companhias provocam reações da sociedade que questiona a sua atuação e sua responsabilidade social, gerando crises corporativas, as quais, por sua vez, acarretam efeitos negativos, principalmente, em relação a sua imagem (SIOMKOS, 1999; KUHN; ASHCRAFT, 2003) e, de modo geral, mudanças nas suas estratégias e operações são por elas experenciadas (BARNETT; PRATT, 2000).

Crises Corporativas são provocadas, conforme Mitroff, Shrivastava e Udwadia (1987, p. 283), por

[...] desastres ocasionados por pessoas, estruturas organizacionais, econômicas e/ou tecnológicas que causam sérios danos à vida humana e o ambiente natural e social [...]. 
sendo os desastres definidos por Vaughan (1999) como acidentes em larga escala, de um custo inestimável e de proporções inesperadas. Crise e desastre são, de modo geral, tratados como sinônimos, porém Shaluf, Ahmadun e Said (2003) observam que ambos são dois eventos diferentes e relacionados, não havendo consenso acerca da sua definição ou de critérios para defini-los. Para os autores, uma crise consiste em "[...] uma situação na qual decisões importantes envolvendo ameaças ou oportunidades devem ser tomadas em um curto espaço de tempo [...]"; já o desastre envolve

[...] procedimentos de gestão que devem ser mantidos, e problemas de gestão enfrentados sob condições de emergência técnica, envolvendo ameaças de lesões e perda de vida. (SHALUF; AHMADUN; SAID, 2003, p. 24).

Os desastres desencadeiam uma crise corporativa, a qual, segundo Weick (1988), caracteriza-se pela baixa probabilidade e alta consequência de ocorrer determinados eventos que ameaçam os objetivos fundamentais de uma organização, ou ainda, como Nystrom e Starbuck (1984, p. 324) consideram, a crise é "[...] uma situação que ameaça seriamente a sobrevivência de uma organização.” Sendo a crise uma incongruência entre as expectativas de uma empresa e o que realmente ocorre (HAYS, 1985), essa desenvolve respostas estratégicas a um ambiente de mudança (BARTLETT; GHOSHAL, 1987), pois a sua capacidade de ser bem sucedida depende da sua estratégia.

Nesse sentido, Preble (1997) argumenta a favor da integração da gestão de crise no processo de gestão estratégica, pois, segundo o autor, esse processo proverá a empresa de uma estratégia para prevenir-se contra o desenvolvimento de eventos que acarretam crises ou mesmo para diminuir seus efeitos no caso de uma crise em curso. Essa aproximação dos estudos de gestão de crises e de gestão estratégica ocorreu nos anos 1980, por estudos conduzidos por Shrivastava e Mitroff (1987) e Smart e Vertinsky (1984), entre outros, e no início dos anos 1990, com os estudos de Mitroff, Pearson e Pauchant (1992) e Pauchant e Mitroff (1992), entre outros.

A gestão de crise é definida por Preble (1997, p. 777) como o

[...] processo sistemático pelo qual uma organização tenta predizer ou identificar crises potenciais que a mesma pode encontrar, tomando precauções para prevenir contra as crises ou minimizar os efeitos das mesmas.

A gestão estratégica compreende a formulação, implementação e avaliação de estratégias para alcançar os objetivos organizacionais (CERTO; PETER, 1993), estabelecer um posicionamento na indústria
(PORTER, 1979), vislumbrar a empresa no seu futuro (HAMEL; PRAHALAD, 1993). Contudo, apesar de fazer planos estratégicos bem delineados, as empresas têm dirigido pouca atenção aos problemas potenciais que podem acontecer e fazer minar os benefícios do processo estratégico (PREBLE, 1997).

Os dois campos, gestão estratégica e gestão de crises, apresentam similaridades e diferenças entre si (PREBLE, 1997). As diferenças são muitas, como a orientação dos processos. Enquanto que os pesquisadores e praticantes da gestão estratégica se orientam, principalmente, pelo desempenho corporativo e pela busca de oportunidades e ameaças para criar e manter uma vantagem competitiva (PORTER, 1979), os estudos de gestão de crise se orientam por questões sobre como as organizações podem ameaçar o ambiente externo e sobre como "corporações sustentáveis" podem ser criadas e mantidas (SHRIVASTAVA, 1993). Ainda, o campo da gestão estratégica considera acionistas, empregados, fornecedores, investidores, governos e clientes como seus principais stakeholders, enquando que, para a gestão de crises, a esses devem ser adicionadas as futuras gerações, grupos específicos de interesse, terroristas, psicopatas, políticas locais e competidores (PREBLE, 1997).

Quanto às similaridades, Preble (1997) sintetiza seis características comuns aos dois processos: foco nas relações ambientais; um conjunto complexo de stakeholders; o envolvimento da alta administração; uma preocupação com toda a organização; a expressão de um padrão consistente; e uma representação de um processo emergente. Tanto o fazer estratégia como o gerir uma crise consiste em uma mistura complexa que reflete consistência e processos emergentes, visto que, nesse último, exige-se uma resposta estratégica.

Os estudos sobre respostas estratégicas à crise corporativa têm recaído no campo dos estudos de comunicação corporativa, pouco se relacionando com a gestão estratégica. Por exemplo, Kim, Averyb e Lariscyc (2009), por meio da análise de conteúdo em periódicos da área de comunicação e negócios, pesquisaram as estratégias de respostas mais efetivas na gestão de crises, focalizando, principalmente, nas práticas de comunicação. Kernisky (1997) pesquisou os boletins publicados durante dez anos depois do crime de Bhopal, em 1984, pela Dow Chemical (A empresa é proprietária da Union Carbide, responsável por um vazamento de gás em Bophal que matou milhares de pessoas em 1984.), analisando a retórica da companhia na gestão de crises, na reparação de sua imagem e na busca de legitimidade. Ainda, entre outros, King III (2006) analisou as respostas estratégicas utilizadas por uma empresa depois de ser acusada de sérias irregularidades e conduta inapropriada.

Todavia, a crise decorrente de uma ação provocada pelos sistemas organizacional, tecnológico e social de 
uma companhia não deve ser respondida tão somente por meio de práticas de comunicação. Ainda a esse respeito, Sapriel (2003, p. 348) afirma que a gestão da crise não deve ser reduzida a "[...] uma função do departamento de comunicação corporativa [...]", e, sim, deve ser pensada de forma estratégica, sendo conduzida e implementada por toda a companhia, ou seja, a gestão de crises precisa garantir os planos, habilidades, processos e ferramentas necessários para facilitar e acelerar as respostas à crise.

Vale ressaltar a análise de Gopinath e Prasad (2012) sobre a compreensão por parte de acadêmicos e praticantes, nos livros textos do ensino de gestão, quanto às operações das multinacionais (MNE). Desafiando a compreensão e a interpretação convencionais acerca da estratégia de internacionalização dos negócios, a qual recai sobre os desafios enfrentados pelas MNEs em ambientes políticos bastante complexos e reguladores, as autoras propõem uma compreensão mais ampla dessas operações, a qual se afasta do gerencialismo ingênuo e considera o contexto sócio-cultural-histórico do local em que a MNE irá atuar.

Crises corporativas podem ser resultantes, também, de um crime corporativo, o qual consiste, para Friedrichs (1996, p. 9), em "[...] atos ilegais e prejudiciais cometidos por dirigentes e funcionários de uma corporação para promover os interesses corporativos [...]", e, para Vaughan (1999, p. 288), em

[...] atos de omissão ou a comissão de pessoas ou grupos de indivíduos desempenhando seus papéis organizacionais que violam regras internas, leis, ou regulamentos administrativos em nome dos objetivos organizacionais.

Para Grabosky e Braithwaite (1987), o crime corporativo envolve crimes cometidos por empresas ou seus agentes contra a sociedade, o meio ambiente, credores, investidores ou concorrentes ou governos, resultantes de imprudência, negligência ou desatenção, podendo ser deliberado ou não. Kramer (1984, p. 18), por exemplo, define crime corporativo como

Atos criminosos (de omissão ou comissão), que são o resultado de decisão deliberada de fazer (ou negligência culposa) por pessoas que ocupam posições chave na estrutura organizacional da empresa, como os executivos ou gerentes.

Assim, esse autor considera que crimes corporativos são decisões corporativas, pois essas são tomadas de acordo com os objetivos estratégicos, procedimentos operacionais e as normas culturais da organização, além de que se destinam a beneficiar a própria organização. Nessa perspectiva, crimes corporativos são, também, e não somente as práticas definidas na teoria do necrocapitalismo de Banerjee (2008, p. 1559), aquelas que "[...] resultam na subjugação da vida ao poder da morte [...]" e "[...] criam estados de exceção que permitem a acumulação [de capital] por espoliação."

O conceito de crimes corporativos mais aceito, comumente, é estreitamente legalista, ou seja, aqueles cujos processos obtiveram condenação da empresa (MOKHIBER, 1995). Todavia, as concepções acerca do que sejam os crimes corporativos, a despeito de tantas lacunas na literatura (SIMPSON, 2003), têm em comum o fato de que se caracterizam por serem cometidos por representantes (gerentes, executivos ou outra denominação) da empresa, em nome dos objetivos corporativos.

Quando se trata de crimes corporativos ambientais, a crise desencadeada leva a empresa a um grau maior de crítica e julgamento público do que outros tipos de crise (KERNISKY, 1997), visto que existe uma expectativa quanto à atuação e responsabilidade social das corporações. Ainda nesses casos, a denominação conferida aos crimes corporativos ambientais difere, como Shrivastava (1992) exemplifica, utilizando o caso de Bhopal: o relatório técnico da Union Carbide refere-se ao caso como um "incidente"; o governo indiano, como um "acidente"; as vítimas, como um "desastre"; e os ativistas sociais consideram-no uma "tragédia", um "massacre" e até mesmo um "genocídio industrial". Sobre Bhopal, Walters (2009) concorda com os criminologistas de que se trata de um crime corporativo, um crime de poder, envolvendo estados e corporações que cometem atos ilegais em nome do lucro.

Os crimes ambientais corporativos abalam a confiança de investidores, consumidores, acionistas e da sociedade em geral, pois as corporações desempenham papel relevante na sociedade moderna, oferecendo produtos e serviços para suprir suas necessidades, demandas e desejos, assumindo a função de provedora de bens e serviços. Todavia, os governos têm responsabilidades fundamentais sobre o bem-estar da população, portanto, quando as corporações, ao produzir bens e serviços, impõem perigos e riscos aos consumidores, aos empregados, à sociedade e ao meio ambiente, os governos atuam no sentido de cumprir o seu papel.

O fato é que, após um crime corporativo ambiental, uma crise corporativa é desencadeada, e a empresa, diante das acusações, toma decisões estratégicas de modo a reparar sua imagem perante o público ou manter os seus relacionamentos com os diversos atores sociais (KERNISKY, 1997; HUANG, 2006), pois, conforme afirmam Stephens, Malone e Bailey (2005), ao responder à crise, as organizações precisam reconhecer um conjunto amplo de stakeholders, incluindo consumidores, a comunidade e outros membros do seu ambiente. Nesses casos, as organizações têm se utilizado da linguagem retórica para reparar um erro de ordem, eminentemente, estratégica. O propósito da comunicação durante uma 
crise é influenciar a percepção do público a fim de manter sua imagem positiva ou restaurar uma imagem danificada perante seus stakeholders (RAY, 1999).

Desse modo, a estratégia comum no decorrer da crise é centrada no discurso dos representantes da companhia e de outros atores, como a mídia, o governo, entre outros. Esse discurso, com o propósito de proteger a imagem da organização, busca modificar a percepção do público quanto à responsabilidade pela crise (COOMBS, 1999) com mensagens estratégicas para controlar os danos e, assim, prevenir mudanças drásticas negativas nos seus relacionamentos (STURGES, 1994) com os diversos stakeholders. Ainda, nos seus discursos estratégicos durante a crise, conforme Lerbinger (1997), a organização aproveita a oportunidade para reforçar, perante o público, sua missão, valores e operações.

\section{$3 \mathrm{O}$ discurso e a prática: abordagens para a pesquisa em estratégia}

Nas pesquisas no campo da estratégia, as abordagens normativas e prescritivas são predominantes, ainda que outras abordagens tenham ganhado espaço. A perspectiva econômica, que forneceu os fundamentos para que o desenvolvimento do campo se tornasse centrado nas concepções de ator individual e racional (KIRSCHBAUM; GUARIDO FILHO, 2011), compartilha espaço agora com a perspectiva sociológica, a qual orienta estudos a partir da natureza social da estratégia organizacional e, no âmbito desses estudos, o discurso tornou-se relevante para a compreensão do modo como as práticas sociais e discursivas influenciam as esferas política e econômica (KIRSCHBAUM; GARIDO FILHO, 2011) e social.

Assim, as abordagens alternativas à econômica, introduzidas na análise da estratégia organizacional, têm como centro a dinâmica do cotidiano no qual as interações sociais ocorrem. Nessa perspectiva, o discurso enquanto prática social ganha importância para a pesquisa em estratégia, visto que é um recurso estratégico (HARDY; PALMER; PHILLIPS, 2000), e é por meio dele que a estrutura social se manifesta (PHILLIPS; SEWELL; JAYNES, 2008). Ainda, é por meio do discurso que as relações de poder, as quais são caracterizadas por contradição, ambiguidade, inconsistência, incerteza e desigualdade, constituem o processo da estratégia.

Nessa direção, estão os argumentos de Hendry (2000) quanto ao fato de que as decisões estratégicas fazem parte do discurso organizacional ou do corpo de comunicações baseadas na linguagem que opera nos níveis da estrutura e da comunicação, constituindo-se em uma característica central do processo da estratégia. Ainda, os estudos de Knights e Morgan (1991, 1995) defendem a concepção de estratégia corporativa como discurso, pois os elementos da estratégia são mobilizados, assim como um discurso, para construir práticas e atores estratégicos. Para defenderem essa ideia, Knights e Morgan (1991, p. 268) baseiam-se na metodologia de Foucault para sugerir que a estratégia, como um discurso, " [...] está intimamente envolvida na constituição de intenções e ações a partir das quais se pensa ser essa [estratégia] derivada." Sendo assim, a análise de estratégia não pode se resumir aos aspectos racionalistas de mercados e ambientes, ou a interpretações dos diversos atores que neles atuam, pois a estratégia não é independente das ações e práticas que a constituem, mas, sim, é parte integrante dessas ações ou práticas que, frequentemente, constituem-se na base para explicações ou justificativas. Nessa perspectiva, a estratégia é um elemento essencial no discurso gerencial e, como tal, precisa ser contextualizada tanto nas mudanças específicas que ocorrem nas organizações, bem como na subjetividade de gestão, visto constituir-se em um mecanismo de poder capaz de

\section{[...] transformar os indivíduos em determinados tipos de sujeitos que garantem uma sensação de bem-estar através da participação em práticas estratégicas [...] (KNIGHTS; MORGAN, 1991, p. 251).}

Argumentando a favor da aplicação da análise crítica de discurso de Fairclough (1992) nos estudos de estratégia, Phillips, Sewell e Jaynes (2008) identificam, na literatura específica do campo, três abordagens que relacionam a linguagem e a formulação e implementação da estratégia: estratégia como um sistema de significados compartilhados; estratégia como texto e discurso; e estratégia como verdade (Quadro 1).

A estratégia como um sistema de significados compartilhados implica no entendimento de que a lógica organizacional pode ser estudada como a criação de significados a partir de recursos discursivos externos à organização para se chegar a um consenso quanto aos seus objetivos estratégicos e os meios para alcançá-los (PHILLIPS; SEWELL; JAYNES, 2008). Nessa direção, Fenton e Langley (2011) exploram as aplicações da narrativa como abordagem para analisar a estratégia como prática, considerando que a narrativa é uma maneira pela qual os significados são criados nas práticas cotidianas, constituindo um sentido de direção ou propósito entre os membros.

A estratégia como texto e discurso tem como foco a construção retórica de textos, sendo o interesse dirigido para o modo como a estratégia é escrita, por quem é escrita (estrategista) e como é disseminada (textos e discursos em torno da estratégia) (PHILLIPS; SEWELL; JAYNES, 2008). A retórica como o ato de persuadir (LEACH, 2002) implica na organização do discurso para ser persuasivo, sendo a persuasão o objeto tradicional da análise retórica. Contudo, o 
Quadro 1. Características das abordagens que relacionam o discurso e a estratégia.

\begin{tabular}{|l|l|l|l|}
\hline & $\begin{array}{c}\text { Estratégia como significados } \\
\text { compartilhados }\end{array}$ & $\begin{array}{c}\text { Estratégia como } \\
\text { texto e discurso }\end{array}$ & \multicolumn{1}{|c|}{ Estratégia como verdade } \\
\hline $\begin{array}{l}\text { Concepção de estratégia } \\
\text { (ontologia) }\end{array}$ & $\begin{array}{l}\text { Manifestação do modo de } \\
\text { legitimação da compreensão } \\
\text { dos objetivos estratégicos e dos } \\
\text { meios para alcançá-los }\end{array}$ & $\begin{array}{l}\text { Uma narrativa } \\
\text { autorizada }\end{array}$ & $\begin{array}{l}\text { Sistema de conhecimento que } \\
\text { determina e exclui o que a } \\
\text { organização pode e não pode } \\
\text { fazer }\end{array}$ \\
\hline $\begin{array}{l}\text { Operacionalização } \\
\text { (epistemologia/ } \\
\text { Metodologia) }\end{array}$ & Estratégia como uma cultura & Estrutura retórica & $\begin{array}{l}\text { Tecnologia de poder que } \\
\text { determina o que é aceitável e o } \\
\text { que não é }\end{array}$ \\
\hline Metodologia adotada & $\begin{array}{l}\text { Quantificação das dimensões } \\
\text { da cultura } \\
\text { (mas potencialmente sujeita a } \\
\text { etnografia qualitativa) }\end{array}$ & $\begin{array}{l}\text { Estudo da construção } \\
\text { de textos ao longo do } \\
\text { tempo }\end{array}$ & $\begin{array}{l}\text { Estudo genealógico dos textos } \\
\text { de estratégia. Estudo etnográfico } \\
\text { de discurso e prática como uma } \\
\text { resposta aos textos estratégicos }\end{array}$ \\
\hline
\end{tabular}

Fonte: Adaptado de Phillips, Sewell e Jaynes (2008).

aspecto principal a ser considerado nesse processo é o contexto do discurso, o qual é " $[$...] produzido por um orador (retor) competente e consciente que organiza seu discurso de acordo com conjuntos de regras formalizadas [...]" (LEACH, 2002, p.296) para persuadir um público específico a se comportar de determinado modo ou modificar um comportamento ou opinião.

No caso da abordagem da estratégia como texto e discurso, a concepção da estratégia é uma narrativa autorizada, o que implica a tentativa de dramatizar a vida organizacional e introduzir histórias de sua performance (PUTNAM; PHILLIPS; CHAPMAN, 2004), as quais são reconstruídas na medida em que elementos novos são adicionados. Para Putnam, Phillips e Chapman (2004), as organizações constroem sua imagem e identidade a partir das narrativas que são contadas por elas próprias, as quais criam significados para que os membros da organização vejam sentido nas suas experiências na organização (BOYCE, 1995). É nesse sentido que Boje (2005) considera as narrativas como prisões, pois, uma vez inscritos em uma história, nós agimos de acordo com as expectativas que os outros têm em relação aos papéis que desempenhamos. Ainda nessa direção, Vendelo (1998) sugere que as narrativas organizacionais constituem-se em um mecanismo para legitimação da organização e garantia de sua reputação.

As narrativas, sem dúvida, são prevalecentes nas organizações, desempenhando um papel central para a legitimação de poder, a construção de identidades individuais e organizacionais e, também, servem de mecanismos implícitos de controle de forma a administrar os significados organizacionais. Entretanto, como ressaltam Putnam, Phillips e Chapman (2004), a análise dos elementos das narrativas pode, também, revelar os paradoxos e as contradições.

A estratégia como verdade focaliza o impacto das interações cotidianas e das políticas da estratégia sobre os membros da organização, sendo o discurso produzido no cotidiano organizacional uma tecnologia do poder, a qual produz e reproduz verdades, cujos efeitos, entre outros, são: a) explica o sucesso ou fracasso de gestão em função da estratégia em questão; b) apresenta os gestores como peritos com acesso privilegiado ao conhecimento; c) legitima o exercício do poder de determinados grupos em detrimento de outros; d) cria categorias para classificar as pessoas em bons gestores, funcionários que resistem à implementação da estratégia (PHILLIPS; SEWELL; JAYNES, 2008). Nesse sentido, Vaara, Sorsa e Palli (2010) utilizaram a análise crítica de discurso para compreender o poder dos planos estratégicos como um gênero diretivo, identificando os discursos centrais neles contidos e suas implicações quanto às relações de poder.

Essas abordagens são complementares na análise da estratégia, como propõem Phillips, Sewell e Janes (2008) no framework desenvolvido para esse fim específico. Considerando os três níveis da análise crítica de discurso de Fairclough (1992), os autores formulam um modelo para análise da mudança estratégica em uma companhia. Para Fairclough (1992), os discursos devem ser analisados, de forma simultânea, em três níveis: texto (micro, implica na análise da estrutura linguística), práticas discursivas (produção e interpretação dos textos) e a prática social (contexto social e institucional - como os textos e discursos - são utilizados).

No modelo de Phillips, Sewell e Janes (2008), o sistema de significados compartilhados, que corresponde ao nível do contexto social do discurso, cria verdades, as quais correspondem ao nível do discurso e que, por sua vez, são também criadas pelos textos e discursos produzidos como respostas aos seus efeitos, o que corresponde ao nível do texto. As companhias, ao fornecerem suas respostas estratégicas à crise decorrente de crimes corporativos, estão imersas na prática social com seus diversos públicos, quais sejam, empregados, fornecedores, parceiros, governo, concorrentes, ativistas, investidores e a sociedade. 


\section{Procedimentos da pesquisa}

Nesta pesquisa, analisamos as respostas estratégicas de uma companhia acusada de um crime corporativo ambiental, utilizando a análise retórica, conforme Reboul (2004), para quem a retórica consiste na arte de persuadir pelo discurso. Nossa análise considera a estrutura retórica a partir de seus quatro elementos: (1) gênero do discurso, que compreende a essência da mensagem, nesse caso, as verdades produzidas por meio do discurso; (2) o orador ou retor, que é aquele que produz o discurso, nesse caso, os representantes da empresa; (3) a audiência, nesse caso, os stakeholders da empresa; e (4) os meios de prova, os quais consistem nos fatos criados, nos exemplos e evidências. A esses elementos, foram adicionados os três argumentos persuasivos da retórica: logos (razão), pathos (emoção) e ethos (ética).

$\mathrm{O}$ primeiro passo da pesquisa consistiu em uma busca no website da empresa para identificar as suas respostas oficiais à crise. Em seguida, buscamos, no Jornal A Folha de S. Paulo, a cobertura jornalística do acontecimento, no período de 7 de novembro de 2011 a 19 de abril de 2012, para identificar a cronologia do caso, as reações da empresa diante da atuação do governo e das manifestações de especialistas e outros organismos. Além de A Folha de S. Paulo, selecionamos uma entrevista do Presidente da Chevron na África e América Latina, na qual este assume uma posição oficial sobre o vazamento. O resultado das duas etapas constitui os textos considerados para análise, dos quais retiramos fragmentos retóricos (REBOUL, 2004) para compor o corpus de pesquisa e, assim, realizar a análise retórica.

\section{Estratégias de respostas após um crime corporativo: o discurso como tentativa de construir verdades}

Para analisar as estratégias de respostas utilizadas pela multinacional Chevron, depois do vazamento no poço de petróleo na plataforma utilizada pela empresa petrolífera norte-americana, na Bacia de Campos/RJ, em novembro de 2011, acompanhamos, inicialmente, a cobertura jornalística realizada pela Folha de S.Paulo no período de 7 de novembro de 2011 a 19 de abril de 2012. Identificamos, nessa busca, 46 reportagens, nas quais analisamos, para identificar a atuação do governo, da Agência Nacional de Petróleo (ANP), do Ministério Público, da Polícia Federal, entre outros, especificamente, acusações e denúncias contra a empresa face ao vazamento que provocou a crise. A escolha por esse jornal deve-se ao fato de ser considerado um dos maiores jornais de circulação do País.

Paralelamente à identificação das acusações e denúncias, acompanhamos as respostas da empresa postadas no website da Chevron Brasil. Fizemos a primeira busca em 16 de novembro de 2011 e, nessa data, constava uma chamada na página inicial: "Comunicado Público ao Campo do Frade". Prosseguindo com a coleta de dados para acompanhar as respostas da empresa, identificamos que essa chamada foi retirada e outra, de "Notícias", passou a conter as atualizações do caso.

Identificamos, no website da empresa, um conjunto de postagens agrupadas em cinco categorias, as quais consideramos como respostas oficiais da empresa.

Em nossa análise do material coletado, tanto no website na empresa quanto nas reportagens jornalísticas, orientamo-nos para identificar: (1) a crise desencadeada: acidente, incidente ou crime? (descrição do caso que desencadeou a crise - a cronologia e os principais eventos, visando à reconstrução do caso para ampliar seu entendimento); (2) os atores envolvidos para identificar as acusações e denúncias, visto que, a essas, a empresa oferece respostas estratégicas; (3) as respostas estratégicas da empresa à crise, que compreendem a análise retórica.

\subsection{A crise desencadeada: desastre, incidente ou crime?}

O vazamento ocorreu no Campo de Frade, na Bacia de Campos, no RJ, operado pela petroleira norte-americana Chevron. A cronologia do caso tem início no dia 7 de novembro de 2011 quando, durante uma perfuração, foi utilizado um tipo de lama sem o peso necessário para conter o óleo, que subiu pelo poço e pelas formações rochosas, chegando ao fundo do mar e vazando por fissuras no solo. No dia 8 de novembro, a mancha foi avistada pela Petrobrás, a qual avisou à Chevron e ao IBAMA. Segundo a Chevron Brasil (2011), a "Equipe de Resposta à Emergência da Chevron é ativada".

No dia 9 de novembro, a Chevron comunica o vazamento à Agência Nacional do Petróleo (ANP) e ao IBAMA. No dia 10 de novembro, as operações no Campo de Frade são suspensas e, no dia 12 de novembro, a Chevron solicita à ANP autorização para selar e abandonar o poço. No dia seguinte, 13, a empresa joga mais lama para conter o vazamento e, no dia 16 de novembro, o poço começa a ser cimentado. No dia 19 de novembro, a ANP informa que o vazamento continua e, no dia 21, o IBAMA multa a empresa.

Desde o dia 8 de novembro de 2011 até o dia 27 de março e 2012, a Chevron tem comunicado as ações da empresa quanto aos reparos técnicos do problema, dia a dia, no seu website, disponibilizando a cronologia de suas respostas estratégicas à crise instaurada pelo vazamento.

As crises desencadeadas por crimes ambientais corporativos tornam a empresa mais vulnerável à crítica e julgamento público (KERNISKY, 1997). A 
complexidade da crise provocada por esses crimes pode ser observada pelas diferentes denominações que lhes são conferidas, como ocorreu com o caso de Bhopal (SHRIVASTAVA, 1992). No caso em análise, por exemplo, para a Procuradoria, o vazamento foi "[...] um dos maiores desastres ecológicos de que se tem notícia no país" (GRILLO; MARTINS, 2012, p. 01), e o procurador Eduardo Santos Oliveira considera, também, que é "uma série de crimes ambientais". Para o delegado Fábio Scliar, da Delegacia de Meio Ambiente e Patrimônio Histórico (DMAPH), o vazamento está configurado como um "crime de poluição" (LUNA, JUNIOR; MARTINS, 2011). A Chevron declara ser um "incidente" (CHEVRON..., 2011).

\subsection{Os atores envolvidos e sua atuação na crise}

A Chevron falhou - A Agência Nacional do Petróleo (ANP) afirma que o vazamento foi causado por problemas de operação da empresa e não por falhas geológicas, conforme informa o diretor da ANP:

Temos que avaliar as causas. No princípio eles argumentaram que o acidente foi por causas naturais, mas não aceitamos, vamos investigar. (LUNA; JUNIOR; MARTINS, 2011, p. 01).

O Governo (procurador) também acusa a empresa da falha técnica, em função de que o revestimento não chegava ao reservatório e o vazamento ocorreu na área não protegida. Para o governo, o vazamento não teria ocorrido se houvesse a camada extra de concreto. Quanto à causa do acidente, o governo (procurador) entende que

[...] a avaliação é que houve coincidência de falhas: aumento inesperado de pressão, vazamento de óleo para dentro da estrutura do poço, escape por rachadura no solo da área de Macaé. (CRUZ; FERNANDES, 2011, p. 01).

O delegado Fabio Scliar considera que "[...] houve problemas na técnica utilizada na perfuração no Campo de Frade" (MARTINS, 2011, p.01), pois as empresas utilizaram, na retirada do petróleo, pressão maior do que as rochas suportavam.

A Chevron foi negligente - A ANP proibiu a Chevron de continuar a perfurar no Brasil. A empresa só poderá voltar à atividade quando as causas do vazamento no Campo de Frade forem identificadas, e as condições de segurança, restabelecidas. Segundo a ANP, houve negligência da Chevron na perfuração de poços e na elaboração e na execução de cronograma de abandono (JUNIOR, 2011a). O procurador Eduardo Santos de Oliveira também acusa a empresa de "negligente", demonstrando incapacidade para operar no País.
A Chevron e seus executivos cometeram um crime - Para o delegado Scliar, da DMAPH, da PF, no Rio, houve crime ambiental, pois, conforme afirma, "O crime de poluição já está configurado" (LUNA; JUNIOR; MARTINS, 2011, p. 01). O secretário de Ambiente do Rio de Janeiro, Carlos Minc, apoiando a ação criminal da Política Federal, entende que à empresa deve ser imposto o máximo de punições, pois "É um sinal vermelho para o pré-sal que vem aí, por isso apoiamos a ação criminal da PF, não pode ficar barato" (LUNA; JUNIOR; MARTINS, 2011, p. 01).

A acusação de crime estendeu-se aos executivos da empresa, inclusive ao presidente da empresa no Brasil, George Buck: "A Polícia Federal indiciou a Chevron e a Transocean e mais 17 executivos das duas empresas pelo vazamento de óleo no Campo de Frade, bacia de Campos, em novembro". Para o delegado Scliar, da DMAPH, as empresas usaram "práticas temerárias" e causaram danos ambientais, além de sonegar informações aos investigadores e entregar documentos falsos à polícia, portanto, o delegado está convencido de que

[...] a política institucional da empresa é temerária e leviana na perfuração de poços de petróleo no Brasil. Por isso, a responsabilização dos executivos (MARTINS, 2011, p. 01).

Segundo o Ministério Público Federal, a Chevron, a Transocean e mais 17 funcionários

[...] teriam, de maneiras distintas, condições de evitar que o vazamento ocorresse. Quatro executivos foram acusados ainda de falsidade ideológica, pois teriam entregue às autoridades imagens editadas do vazamento." (GRILLO; MARTINS, 2012, p. 01).

A Chevron esconde os fatos - A acusação de que a empresa mascara os fatos, encobrindo a situação real, é compartilhada por vários atores. O Greenpeace manifestou-se de forma a duvidar das declarações da empresa (EXPLORAÇÃO..., 2011) de que o vazamento foi causado por uma falha natural na superfície do fundo do mar. Porém, essa falha não foi apontada no Estudo de Impacto Ambiental (EIA). Assim, o Greenpeace lança a questão: "O que aconteceu? Onde está o EIA de Frade?” (EXPLORAÇÃO..., 2011).

A Polícia Federal (PF) "[...] abriu inquérito para investigar crime de poluição no caso de vazamento [...]" (JUNIOR; MARTINS, 2011, p. 01) depois de constatar que o combate ao vazamento não estava sendo realizado conforme a empresa manifestou. Agentes federais sobrevoaram o local e encontraram apenas uma embarcação cuidando da limpeza, e não as 18 como a empresa afirmou. A entrada da PF no caso se deu a pedido da Presidência da República, que pediu rigor na apuração dos fatos (JUNIOR; MARTINS, 2011). 
As informações prestadas pela empresa à PF e à opinião pública são distintas acerca do que realmente acontece, conforme destacou o delegado da DMAPH: "Inicialmente, os relatórios não correspondem à realidade dos fatos. Quero entender o que ocorre" (JUNIOR; MARTINS, 2011, p. 01). Além disso, o delegado informou sobre sua pretensão de contatar o consulado norte-americano, pois soube que uma autoridade ambiental dos EUA visitou o local sem que a PF fosse comunicada. Como denúncia de que a empresa esconde os fatos, o geógrafo John Amos, diretor do site SkyTruth, especialista em interpretação de fotos de satélites com fins ambientais, estima que o derrame pode chegar a 3.738 barris por dia, e não a 330 barris/dia, como a empresa informou (JUNIOR; MARTINS, 2011). Ainda, a ANP declarou que a empresa enviou "informações truncadas" ao governo (SOARES; JUNIOR; FOREQUE, 2011).

A Chevron impõe riscos e perigos ao meio ambiente - Vários especialistas foram envolvidos no caso. O oceanógrafo David Zee, por exemplo, afirmou que "Embora remota, a possibilidade de a mancha de óleo atingir a costa do Rio de Janeiro ainda existe." Ainda, o especialista afirmou que os efeitos para o ecossistema são inevitáveis (JUNIOR; MARTINS, 2011, p. 01). O governo do Rio entrou com ação civil pública para reparações ambientais em razão do vazamento (JUNIOR, 2011b).

O delegado da DMAPH informou ainda haver estudo de impacto ambiental feito pela própria Chevron em que a empresa previa que um vazamento de óleo no campo causaria danos à flora e à fauna.

No estudo, a própria Chevron relata que um vazamento iria interferir na cadeia alimentar de peixes maiores e, consequentemente, até câncer em seres humanos.

Laudos do IBAMA e do oceanógrafo David Zee, anexados ao inquérito, são usados para comprovar que o vazamento causou danos (MARTINS, 2011, p. 01).

\subsection{Gestão da Crise e estratégia}

Como advogam Pauchant e Mirtroff (1992) e Preble (1997), a gestão da crise é de natureza estratégica, o que deve ser reconhecido pelos top management. A crise protagonizada pela Chevron ganhou dimensões tais que ameaça a sua atuação na exploração do pré-sal no Brasil (LUNA; JUNIOR; MARTINS, 2011), além de envolver o governo e a sociedade civil organizada, fazendo com que a empresa responda a acusações e denúncias. As respostas da empresa evidenciam a ausência de integração dos processos de gestão estratégica e de crise, o que é comum, segundo diversos autores (MITROFF; SHRIVASTAVA; UDWADIA, 1987; PREBLE, 1997).

Embora o vazamento tenha ocorrido na sua área, no dia 7 de novembro, a empresa soube do vazamento um dia depois, pela Petrobrás e, ao ser contatada, fez uma pesquisa no local, não encontrando nenhum problema. No dia seguinte, em 9 de novembro, a empresa verificou que havia o vazamento. Nas postagens da empresa, no seu website, a empresa afirma ter uma "equipe de resposta à emergência", que agiu, imediatamente, nos trabalhos de controle da mancha e análise para detectar sua causa. Uma das medidas da empresa foi a suspensão das atividades de perfuração no campo e fechamento do poço que estava sendo perfurado (CHEVRON..., 2011). Conforme as informações da Chevron Brasil (2011), somente dez dias depois, havia uma equipe para monitoramento do poço.

Todavia, a existência de um processo de gestão de crise não foi evidenciada, já que esse envolve, na sua primeira fase, a realização de uma avaliação de risco para identificar as ameaças potenciais, probabilidades de ocorrência e, principalmente, a determinação de impactos (PREBLE, 1997). Segundo as denúncias e acusações, a empresa, quando não omitiu, forneceu informações falsas e desencontradas. A empresa afirmou a existência de um "Plano de Emergência Individual (PEI) que foi devidamente aprovado pelo INEA/IBAMA)" (CHEVRON..., 2011, p.01), contudo, esse não é um plano integrado à gestão estratégica.

Os planos de contingência (PREBLE, 1997), comumente, assumem que a crise vai seguir um caminho predizível e, assim, focalizam em alternativas futuras ao plano estratégico, o que orienta a sua elaboração para a limitação dos danos, negligenciando a prevenção de crises. Ainda, no decorrer da crise, houve uma ameaça de novo vazamento, o que reforça a falta de integração entre os dois processos (gestão crise e estratégia):

No início de março de 2012, a Chevron identificou um novo pequeno afloramento de óleo no Campo de Frade. A empresa irá realizar um amplo estudo técnico e preparar um estudo complementar para o melhor entendimento da estrutura geológica da área, trabalhando com os parceiros (CHEVRON..., 2011, p. 01).

As respostas estratégicas na gestão de crises têm recaído no campo da comunicação corporativa (KIM; AVERYB; LARISCYC, 2009; KING III, 2006; KERNISKY, 1997), que analisa essas respostas de acordo com as categorias de reparação de imagem. Porém, a gestão de crises tem profunda relação com a estratégia corporativa. Uma questão mencionada na introdução deste artigo diz respeito ao modo como essa relação pode ser configurada. O processo de gestão estratégica elaborado a partir dos pressupostos das teorias funcionalistas (KIRSCHBAUM; GUARIDO FILHO, 2011) pode contemplar o processo de gestão de crise de forma a integrá-lo nas suas diversas fases, como o modelo sugerido por Preble (1997). Todavia, as 
abordagens sociológicas, nas quais se inclui a análise de discurso (HARDY; PALMER; PHILLIPS, 2000; PHILLIPS; SEWELL; JAYNES, 2008; HENDRY, 2000; KNIGHTS; MORGAN, 1991, 1995), são capazes de oferecer uma nova compreensão do processo de gestão de crise no processo de estratégia.

Durante a crise corporativa, os executivos tendem a redefinir a realidade com suas próprias fantasias e crenças (MITROFF et al., 1989) ou mesmo distorcer sua interpretação dos sinais de perigos emitidos da dinâmica do sistema organizacional-social-cultural (PREBLE, 1997). Assim, nos seus textos/discursos em resposta à crise, os executivos evocam significados exteriores à organização para criar sistemas de verdade, os quais compreendem os discursos internos produzidos para sustentar as respostas às denúncias e acusações dirigidas à corporação no decorrer da crise. Apresentadas as posições dos atores externos à empresa envolvidos na crise, analisamos, a seguir, as verdades produzidas pela Chevron, em resposta à crise.

\subsection{Análise retórica: Strategy as truth}

Ancorados no modelo de Phillips, Sewell e Janes (2008), analisamos as respostas da empresa, identificando os textos ou discursos produzidos pela empresa para criar significados compartilhados e para produzir as verdades quanto à crise com a qual a empresa está lidando, conforme Figura 1.

Extraímos dos textos analisados quatro verdades principais, reconhecendo não serem essas as únicas. Essas verdades são consideradas aqui como o primeiro elemento da análise retórica, qual seja, o gênero do discurso, e apresentamos os outros elementos da estrutura retórica (REBOUL, 2004): o orador (nesse caso, identificando quem representa a empresa), a audiência e os meios de prova.

Verdade 1: "Foi a mãe natureza" - Em entrevista concedida à Revista Carta Capital, Alli Moshiri culpou a 'mãe natureza' e a complexidade geológica da região pelo vazamento de petróleo:

Estamos lidando com a mãe natureza e ela é complicada. Cada parte do reservatório é diferente, mas temos pessoal altamente qualificado trabalhando nisso. Devemos fazer uma avaliação mais detalhada para ter certeza de que não acontecerá de novo (CARTA CAPITAL, 2011, p. 23).
A empresa é acusada de ter falhado nas suas operações, ao que respondeu, transferindo a culpa pelo ocorrido a problemas de natureza geológica. No depoimento do representante da empresa, este faz uma alusão sobre os desafios da atividade de exploração marítima:

Tanto a Chevron quanto os demais operadores do mercado, assim como os reguladores do setor, sabem e reconhecem os grandes desafios que a exploração em águas profundas oferece (CHEVRON..., 2011, p. 01).

Ainda, o representante afirma que, no dia seguinte ao acidente, a empresa detectou a mancha em um procedimento de rotina: "No dia 8 de novembro, uma mancha foi detectada em sobrevoo de rotina".

Verdade 2: Não há perigo ou risco ao meio ambiente - No seu depoimento, o representante da Chevron afirma que

Contrariamente ao que foi noticiado, o contínuo monitoramento e as análises disponíveis indicam que os incidentes não causaram dano a pessoas ou ao meio ambiente, aí incluídas fauna e flora marinhas. (CHEVRON..., 2011, p. 01)

Os oradores contradizem os especialistas que afirmaram ser o dano inquestionável. Para a empresa, essa acusação não tem fundamento, pois

O monitoramento contínuo da área do incidente mostra não ter havido nenhum impacto ambiental para a vida marinha. Nenhum petróleo chegou à costa do Brasil. Nenhuma pessoa foi prejudicada em consequência do incidente e não há base técnica para supor que houve algum risco para a saúde humana (CHEVRON..., 2011, p. 01).

Verdade 3: Não cometemos um crime - Às acusações de ter cometido um crime, a empresa responde, tratando do vazamento como um incidente. Para a empresa, o "Indiciamento criminal não tem mérito" (CHEVRON..., 2011), e a empresa é vítima de

[...] uma série ultrajante de ações impetradas pelo mesmo promotor que anteriormente ajuizou ações criminais e civis igualmente absurdas. (CHEVRON..., 2011, p. 01)

O valor da ação, para a empresa, "é arbitrário e especulativo e não está baseado em fatos". A empresa mostra-se confiante de que sua inocência será provada:
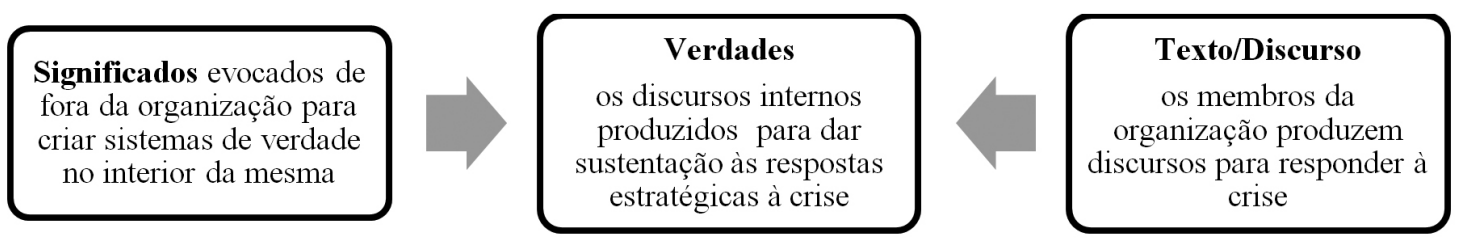

Figura 1. Análise da relação entre discurso e estratégia. Fonte: Elaborado pelos autores. 
Como nas ações civil e criminal anteriores, estamos confiantes de que uma análise transparente e imparcial dos fatos demonstrará que a Chevron e seus empregados responderam de forma responsável e apropriada ao incidente. A Chevron irá defender com vigor a reputação de seus colaboradores e da empresa. (CHEVRON..., 2011, p. 01)

Verdade 4: Somos responsáveis - A empresa afirma seu compromisso em resolver a crise: "Nós temos o compromisso de mobilizar todos os recursos até a mancha não poder mais ser detectada" (CHEVRON..., 2011, p. 01).

Em seu depoimento, o representante da empresa reafirma o seu esforço:

Entretanto, em 15 de março, a Chevron lançou mão do seu processo interno denominado "stop work authority", baseado em sua política global de excelência operacional, que incentiva e premia seus colaboradores a terem a iniciativa de alertar para riscos e, consequentemente, solicitar a paralisação dos trabalhos, de modo a garantir segurança e proteção a seu pessoal e ao meio ambiente. (CHEVRON..., 2011, p. 01)

Esse texto cria uma verdade cujo significado, do crime corporativo, pode ser interpretado pelos funcionários como uma fatalidade.

A Chevron Brasil (2011, p. 01) responde às denúncias, afirmando que

[...] sempre agiu dentro dos mais altos padrões de segurança e integridade e está empenhada em esclarecer todos os fatos que estão sendo levantados pela mídia [...]" e "[...] continua trabalhando, em parceria com os órgãos do governo brasileiro, para conter e eliminar a mancha de óleo.

Além disso, a empresa

[...] também assume total responsabilidade pelo incidente e apresentou uma estimativa do volume total do petróleo proveniente das linhas de exsudação no fundo do oceano.

Assim, a companhia, ao responder à crise, aproveita a oportunidade para gerenciar a impressão do público sobre si (STURGES, 1994), reforçando sua missão, seus valores e operações (LERBINGER, 1997).

As respostas estratégicas às acusações contra a empresa têm como oradores o presidente da Chevron para a África e a América Latina, representante da empresa no Brasil, o setor responsável pela comunicação corporativa da empresa, os especialistas contratados pela empresa para opinar sobre o caso, e, ainda, os autores das notícias veiculadas na imprensa e, seletivamente, postadas no website da empresa. Em seu depoimento, o representante da empresa, Williamson, estende a autoria aos colegas e colaboradores:
Em nome de meus colegas e colaboradores na Chevron, agradeço a oportunidade de relatar os fatos dos últimos meses e de reafirmar nosso compromisso com o Brasil, com suas leis e com seu meio ambiente (CHEVRON..., 2011, p. 01).

Ainda, o orador aproveita a oportunidade para reforçar os valores da companhia e demonstra um esforço em tentar manter uma imagem positiva, que é um dos objetivos dos discursos durante a crise, conforme Sturges (1994) e Lerbinger (1997).

Quanto à audiência, a empresa dirige-se para o conjunto amplo de stakeholders da empresa - investidores, acionistas, empregados, governo e a sociedade civil organizada -, buscando reparar sua imagem ou manter a imagem positiva para o público (STEPHENS; MALONE; BAILEY, 2005). Os meios de prova oferecidos pela empresa são as fotos e vídeos postados no seu website, mostrando os equipamentos da empresa em atividade no mar e o esforço da empresa em assumir suas responsabilidades e resolver a crise. Além das fotos e vídeos, mapas geográficos, simulações e outros recursos visuais com explicações técnicas são colocados como provas de suas verdades construídas em resposta à crise, as quais, por sua vez, estão vinculadas a três dimensões da retórica: a lógica, a emocional e a ética.

Em relação ao logos, que corresponde aos aspectos racionais e lógicos, as verdades são construídas utilizando-se da opinião de especialistas no assunto. $\mathrm{Na}$ categoria "Na Mídia" (Quadro 2), foram selecionadas as notícias e opiniões veiculadas na imprensa favoráveis à empresa. Como exemplo, entre outros, citamos a opinião de Rodolfo Landin, publicada da Folha de S. Paulo, em 13 de abril de 2012, a qual se inicia ponderando sobre as conclusões precipitadas. Além da opinião de outros especialistas, a empresa postou no seu website mapas geológicos e outras explicações técnicas. Quanto ao pathos, que compreende os aspectos emocionais, as verdades carregam a emoção de serem injustiçados (a empresa, executivos e empregados) e o sentimento de colaboração, amizade, parceria entre os empregados, os quais são referidos como colaboradores.

O ethos, que diz respeito aos aspectos éticos, encontra-se presente na evocação dos valores nos quais acredita, nos seus deveres, e, ainda, no seu empenho em solucionar a crise:

A Chevron está absolutamente empenhada, por si e em colaboração com seus parceiros e autoridades, em solucionar esse incidente e em contribuir para a melhoria dos procedimentos de prevenção, ação de contenção e transparência nos eventos dessa natureza, como um dever que nos é imposto, desde logo, pelos valores nos quais acreditamos e que defendemos, no Brasil e em todos os lugares em que operamos no mundo (CHEVRON..., 2011, p. 01). 
Quadro 2. Postagens no website da companhia no período de 7/11/2011 a 19/4/2012.

\begin{tabular}{|c|c|c|c|}
\hline Categoria & Característica & $\begin{array}{l}\text { Quant. de } \\
\text { posts }\end{array}$ & Período \\
\hline $\begin{array}{l}\text { Entenda o } \\
\text { incidente }\end{array}$ & $\begin{array}{l}\text { Explicações sobre o vazamento no Campo de Frade e sobre a } \\
\text { participação da Chevron na audiência pública do Senado. }\end{array}$ & 2 & s/data \\
\hline $\begin{array}{l}\text { Comentários à } \\
\text { imprensa }\end{array}$ & $\begin{array}{l}\text { Comunicados oficiais da empresa sobre o andamento das operações } \\
\text { da empresa e respostas às acusações e denúncias, as medidas } \\
\text { tomadas. }\end{array}$ & 14 & $\begin{array}{l}10 / 11 / 2011 \\
\text { a } \\
4 / 4 / 2012\end{array}$ \\
\hline Na mídia & $\begin{array}{l}\text { Notícias veiculadas no Brasil Econômico, na Folha de S. Paulo e no } \\
\text { Globo sobre a empresa e o vazamento. }\end{array}$ & 9 & $\begin{array}{l}22 / 11 / 2012 \\
\text { a } \\
19 / 4 / 2012\end{array}$ \\
\hline Fotos & $\begin{array}{l}\text { Fotos produzidas por técnicos da empresa dos equipamentos de } \\
\text { contenção no ponto de afloramento, da mancha provocada pelo } \\
\text { vazamento, do contêiner com o tanque de armazenamento, dos } \\
\text { pontos de afloramento de óleo, da instalação do equipamento de } \\
\text { contenção, da embarcação dedicada à atividade de limpeza, do óleo } \\
\text { residual, da mancha reduzida, das embarcações contratadas para } \\
\text { dispersar e reduzir a mancha. }\end{array}$ & 22 & $\begin{array}{l}19 / 11 / 2011 \\
\text { a } \\
23 / 12 / 2011\end{array}$ \\
\hline Vídeos & $\begin{array}{l}\text { Vídeos produzidos pela empresa sobre o caso. De modo geral, os } \\
\text { vídeos mostram os equipamentos de contenção em atividade, o } \\
\text { local onde houve o vazamento sem a presença da mancha, os pontos } \\
\text { de afloramento e o monitoramento que a empresa fez depois do } \\
\text { ocorrido. }\end{array}$ & 19 & $\begin{array}{l}28 / 11 / 2011 \\
\mathrm{a} \\
13 / 3 / 2012\end{array}$ \\
\hline
\end{tabular}

Fonte: Dados de pesquisa.

Em nossa pesquisa, apontamos os principais atores que se posicionam quando ocorre uma crise decorrente de um crime ambiental corporativo. Nos processos de crise em que se cogita afetar o bem-estar da população, os governos e a sociedade civil organizada atuam de forma a desempenhar seu papel. Nossa escolha em adotar a análise retórica como técnica de análise aponta para o fato de que as verdades são produzidas no "fazer estratégia", e, ainda, este estudo aponta para a importância dos significados no contexto social da organização, bem como seus efeitos.

\section{Considerações finais}

Neste artigo, nós analisamos as estratégias de respostas utilizadas pela multinacional Chevron, depois do vazamento no poço de petróleo na plataforma utilizada pela empresa petrolífera norte-americana, na Bacia de Campos/RJ, em novembro de 2011. A nossa abordagem é de natureza sociológica e buscou relacionar o discurso e a estratégia em uma situação de crise corporativa.

No caso em questão, a empresa cometeu um crime ambiental corporativo, o qual desencadeou uma crise que exigiu dela respostas estratégicas. Evidenciamos que a gestão de crise, para a Chevron, não está integrada à estratégia da empresa. Quando os dois processos estão integrados, as crises são tratadas de forma preventiva. Nenhuma empresa está livre de uma crise. Porém, um crime corporativo pode ser evitado se houver um esforço dos executivos.

A abordagem da estratégia como verdade, diferentemente das abordagens do mainstream, não focalizam o impacto da estratégia no desempenho empresarial, mas, sim, os impactos do dia a dia dos efeitos sociais e políticos da estratégia sobre a conduta dos membros da organização. No caso da Chevron, as verdades produzidas visavam a convencer os seus stakeholders de que não é culpada pelo vazamento, não é ineficiente, é uma empresa responsável e, principalmente, não cometeu um crime. Os textos (discursos) produzidos e postados no website da empresa foram elaborados para responder à crise após o vazamento, constituindo-se em tecnologias de poder produzidas para dar sustentação às respostas estratégicas à crise. Esses discursos (re)produzem outros discursos, interna e externamente, criando, assim, sistemas de significados compartilhados que, por sua vez, tornam-se verdades.

As respostas estratégicas da Chevron à crise constituem-se nas narrativas autorizadas que determinam e exclui o que é aceitável ou não. Nessa perspectiva, o crime ambiental cometido pela empresa está autorizado. O que se exclui do sistema de conhecimento criado pela empresa para responder à crise e, consequentemente, seus efeitos no cotidiano da empresa, é a sua culpabilidade pelo vazamento, suas falhas técnicas e sua irresponsabilidade.

Esta pesquisa tem implicações teóricas e práticas. Quanto às teóricas, apontamos para a introdução 
de estudos dos crimes corporativos e das crises no âmbito dos estudos de estratégia, principalmente, para desnaturalizar o fenômeno da estratégia. Além de buscar explicações para estratégias planejadas bem sucedidas, sugere-se que o campo se volte para a análise desses eventos e, assim, possa iluminar caminhos para que as companhias e os governos dirijam seus esforços para produzir bens e serviços voltados para o bem-estar da população. Ainda, seguindo o caminho da análise de Gopinath e Prasad (2012), apontamos para a necessidade de incluir os crimes corporativos na pauta do ensino de internacionalização de negócios, bem como de estratégia em geral.

As implicações de ordem prática são diversas. Entre elas, apontamos que, ao relacionar o discurso e a estratégia, estamos apontando os efeitos da estratégia como verdade (PHILLIPS; SEWELL; JANES, 2008), quando executivos e top managers criam verdades como forma de legitimar o papel social das corporações, podendo tornar a companhia propensa a cometer crimes corporativos e, consequentemente, a crises corporativas.

\section{Referências}

BANERJEE, S. B. Necroptalism. Organization Studies, v. 29, n. 12, p. 1541-1565, 2008.

BARNETT, C. K.; PRATT, M.G. From threat-rigidity to flexibility - Toward a learning model of autogenic crisis in organizations. Journal of Organizational Change Management, v. 13, n. 1, p. 74-88, 2000. http://dx.doi. org/10.1108/09534810010310258

BARTLETT, C.; GHOSHAL, S. Managing across borders: New strategic requirements. Sloan Management Review, p. 7-17, 1987.

BOJE, D. Storytelling Organization Survival Manual: Theory and Practice. Thousand Oaks: Sage, 2005 PMid:16101848.

BOYCE, M. E. Collective Centring and Collective Sensemaking in the Stories and Storytelling of One Organization. Organization Studies, v. 16, n. 1, p. 107-137, 1995. http://dx.doi.org/10.1177/017084069501600106

CARTA CAPITAL. Foi a mãe natureza, diz executivo da Chevron sobre acidente. Carta Capital, 24 nov. 2011.

CERTO, S. C.; PETER, J. P. Administração Estratégica: planejamento e implantação da estratégia. São Paulo: Makron Books, 1993. PMid:8152564.

CHEVRON BRASIL. Comunicados a imprensa. Chevron, 2011. Disponível em: <http://www.chevron.com.br/ noticias/press-releases.aspx>. Acesso em: 10 abr. 2012.

CHILD, J. The international crisis of confidence in corporations. Academy of Management Executive, v. 16, n. 3, p. 145-147, 2002. http://dx.doi.org/10.5465/ AME.2002.8540401

CLINARD, M. B. et al. Illegal corporate behavior. Washington: National lnstitute of Law Enforcement and Criminal Justice, 1979.

COOMBS, W. T. Ongoing crisis communication: Planning, managing and responding. Thousand Oaks: Sage, 1999.
CRUZ, V.; FERNANDES, S. ANP quer elevar rigor em normas de segurança. Folha de São Paulo, 24 nov. 2011. Poder.

EXPLORAÇÃO no pré-sal é posta em dúvida. Folha de São Paulo, 17 nov. 2011. Mercado.

FAIRCLOUGH, N. Discourse and social change. Cambridge: Polity Press, 1992.

FENTON, A.; LANGLEY, C. Strategy as Practice and the Narrative Turn. Organization Studies, v. 32, p. 11711198, 2011. http://dx.doi.org/10.1177/0170840611410838

FRIEDRICHS, D. O. Trusted criminals. Belmont: Wadsworth, 1996.

GOPINATH, C.; PRASAD, A. Toward a critical framework for understanding MNE operations: revisiting CocaCola's exit from India. Organziation, p. 1-21, 2012.

GRABOSKY, P.; BRAITHWAITE, J. Corporate crime in Australia. Trends \& Issues in Crime and Criminal Justice. Australian Institute of Criminology, n. 5, 1987.

GRILLO, C.; MARTINS, M. A. Chevron é denunciada por vazamento. Folha de São Paulo, 22 mar. 2012. Mercado.

HAMEL, G.; PRAHALAD, C. K. Strategy as stretch and leverage. Harvard Business Review, v. 71, n. 2, p. 75-84, 1993. PMid:10124635.

HARDY, C.; PALMER, I.; PHILLIPS, N. Discourse as a strategic resource. Human Relations, v. 53, p. 12271248, 2000. http://dx.doi.org/10.1177/0018726700539006

HAYS, R. E. Corporate Crisis Management as Adaptive Control. Corporate Crisis Management. Princeton: Ed. S. J. Andriole, Petrocelli, Inc., 1985.

HENDRY, J. Strategic decision making, discourse, and strategy as social practice. Journal of Management Studies, v. 37, n. 7, p. 955-978, 2000. http://dx.doi. org/10.1111/1467-6486.00212

HUANG, H. Crisis Situations, Communication Strategies, and Media Coverage: A Multicase Study Revisiting the Communicative Response Model. Communication Research, v. 33, n. 3, p. 180-205, 2006. http://dx.doi. org/10.1177/0093650206287077

JUNIOR, C.; MARTINS, M. A. PF investiga negligência após vazamento. Folha de São Paulo, 17 nov. 2011. Mercado.

JUNIOR, C. Agência proíbe Chevron de perfurar no país. Folha de S. Paulo, São Paulo, 24 nov. 2011a. Poder.

JUNIOR, C. Prejuízo da Chevron com vazamento já chega a US\$ 40 milhões. Folha de S. Paulo, São Paulo, 25 nov. 2011b. Mercado. Disponível em: <http://www1.folha. uol.com.br/mercado/1011866-prejuizo-da-chevroncom-vazamento-ja-chega-a-us-40-milhoes.shtml>. Acesso em: 10 abr. 2012.

KERNISKY, D. A. Proactive Crisis Management and Ethical Discourse: Dow Chemical's Issues Management Bulletins 1979-1990. Journal of Business Ethics, v. 16, p. 843-853, 1997. http://dx.doi. org/10.1023/A:1017901501108

KIM, S.; AVERYB, E. J.; LARISCYC, R. W. Are crisis communicators practicing what we preach?: An evaluation of crisis response strategy analyzed in public relations research from 1991 to 2009. Public Relations Review, v. 35, p. 446-448, 2009. http://dx.doi.org/10.1016/j. pubrev.2009.08.002

KING III, G. Image restoration: An examination of the response strategies used by Brown and Williamson after 
allegations of wrongdoing. Public Relations Review, v. 32, p. 131-136, 2006. http://dx.doi.org/10.1016/j. pubrev.2006.02.006

KIRSCHBAUM, C.; GUARIDO FILHO, E. R. Perspectivas sociológicas da Estratégia em organizações: Uma introdução ao fórum. Revista de Administração Mackenzie, v. 12, n. 6, p. 14-27, 2011. http://dx.doi. org/10.1590/S1678-69712011000600002

KNIGHTS, D.; MORGAN, G. Corporate strategy, organizations and subjectivity: A critique. Organization Studies, v. 12, p. 251-273, 1991. http://dx.doi. org/10.1177/017084069101200205

KNIGHTS, D.; MORGAN, G. Strategy under the microscope: Strategic management and IT in financial services. Journal of Management Studies, v. 32, p. 191-214, 1995. http://dx.doi.org/10.1111/j.1467-6486.1995.tb00340.x

KRAMER, R. Corporate criminality: The development of an idea. In: HOCHSTEDLER, E. (Ed.). Corporations as criminals. Beverly Hills: Sage, 1984.

KUHN, T.; ASHCRAFT, K. L. Corporate Scandal and the Theory of the Firm. Management Communication Quarterly, v.17, n. 1, p. 20-57, 2003. http://dx.doi. org/10.1177/0893318903253421

LEACH, J. Análise retórica. In: BAUER, M. W.; GASKELL, G. Pesquisa Qualitativa com texto, imagem e som. Um manual prático. Petropólis: Vozes, 2002.

LERBINGER, O. The crisis manager facing risk and responsibility. Mahwah: Lawrence Erlbaum, 1997.

LUNA, D.; JUNIOR, C.; MARTINS, M. A. Vazamento diminui, mas mancha cresce. Folha de São Paulo, São Paulo, 18 de nov. 2011. Mercado.

MARTINS, M. A. PF indicia Chevron e mais 17 por vazamento de óleo na bacia de Campos. Folha de S. Paulo, São Paulo, 21 dez. 2011. Mercado. Disponível em: <http://www1.folha.uol.com.br/ mercado/1024863-pf-indicia-chevron-e-mais-17-porvazamento-de-oleo-na-bacia-de-campos.shtml>. Acesso em: 10 abr.2012.

MINTZBERG, H.; AHLSTRAND, B.; LAMPEL, J. Safári de Estratégia: um roteiro pela selva do planejamento estratégico. Porto Alegre: Bookman, 2000.

MITROFF, I. I.; SHRIVASTAVA, P.; UDWADIA, F. E. Effective Crisis Management. Academy of Management Executive, v. 1, n. 4, p. 283-292, 1987. http://dx.doi. org/10.5465/AME.1987.4275639

MITROFF, I. I. et al. Do (some) organizations cause their own crises? Culture profiles of crisis prone versus crisis prepared organizations. Industrial Crisis Quarterly, v. 3, p. 269-283, 1989.

MITROFF, I. I.; PEARSON, C.; PAUCHANT, T. C. Crisis management and strategic management: similarities, differences and challenges. Advances in Strategic Management, v. 8, p. 235-60, 1992.

MOKHIBER, R. Crimes corporativos. São Paulo: Scritta, Página Aberta, 1995.

NYSTROM, P. C.; STARBUCK, W. H. To avoid organizational crises, unlearn. Organizational Dynamics, v. 12, p. 53-65, 1984. http://dx.doi. org/10.1016/0090-2616(84)90011-1

PAUCHANT, T. C.; MITROFF, I. Transforming the Crisis-Prone Organization. San Francisco: Preventing
Individual, Organizational and Environmental Tragedies, Jossey-Bass Publishers, 1992.

PHILLIPS, N.; SEWELL, G.; JAYNES, S. Applying Critical Discourse Analysis in Strategic Management Research. Organizational Research Methods, v. 11, n. 4, p. 770-789, 2008. http://dx.doi. org/10.1177/1094428107310837

PORTER, M. E. How competitive forces shape strategy. Harvard business Review, v. 57, n. 2, p. 137-145, 1979.

PREBLE, J. Integrating the Crisis Management Perspective into the Strategic Management Process. Journal of Management Studies, v. 34, n. 5, p. 769-791, 1997. http://dx.doi.org/10.1111/1467-6486.00071

PUTNAM, L. L.; PHILLIPS, N.; CHAPMAN, P. Metáforas da Comunicação e da Organização. In: CLEGG, S. R.; HARDY, C.; NORD, W. R. Handbook de Estudos Organizacionais. Ação e análise organizacionais. São Paulo: Atlas, 2004. v. 3, p. 77-125.

RAY, S. J. Strategic communication in crisis management lessons from the airline industry. Westport: Quorum, 1999.

REBOUL, O. Introdução à retórica. São Paulo: Martins Fontes, 2004.

SAPRIEL, C. Effective crisis management: Tools and best practice for the new millennium. Journal of Communication Management, v. 7 n. 4, p. 348-355, 2003. http://dx.doi.org/10.1108/13632540310807485

SHALUF, I. M.; AHMADUN, F.; SAID, A. M. A review of disaster and crisis. Disaster Prevention and Management, v. 12 n. 1, p. 24-32, 2003. http://dx.doi. org/10.1108/09653560310463829

SHRIVASTAVA, P.; MITROFF, I. I. Strategic Management of corporative cirses. Columbia Journal of World Business, v. 22, n. 1, p. 5-11, 1987.

SHRIVASTAVA, P. Bhopal, Anatomy of a Crisis. London: Paul Chapman Publishing, 1992.

SHRIVASTAVA, P. Crisis theory/practice: towards a sustainable future. Organization \& Environment, v. 7, p. 23-42, 1993. http://dx.doi. org/10.1177/108602669300700103

SIMPSON, S. S. The criminological enterprise and corporate crime. Criminologist, v. 28, n. 4, p. 3-5, 2003.

SIOMKOS, G. J. On achieving exoneration after a product safety industrial crisis. Journal of Business \& Industrial Marketing, v. 14, n. 1 p. 17-29, 1999. http://dx.doi. org/10.1108/08858629910254076

SMART, C.; VERTINSKY, I. Strategy and the environment: A study of corporate response to crises. Strategic Management Journal, v. 5, p. 199-214, 1984. http:// dx.doi.org/10.1002/smj.4250050302

SOARES, P.; JUNIOR, C.; FOREQUE, F. Chevron pode ser punida em R $\$ 260$ milhões por vazamento no Rio. Folha de S. Paulo, São Paulo, 22 nov. 2011. Mercado. Disponível em: <http://www1.folha.uol.com. $\mathrm{br} / \mathrm{mercado} / 1010086$-chevron-pode-ser-punida-em-r260-milhoes-por-vazamento-no-rio.shtml>.

STEPHENS, K. K.; MALONE, P. C.; BAILEY, C. M. Communicating with stakeholders During a Crisis : Evaluating Message Strategies. Journal of Business Communication, v. 42, n. 4, p. 390-419, 2005. http:// dx.doi.org/10.1177/0021943605279057 
STURGES, D. L. Communicating through crisis. Management Communication Quarterly, v. 7, p. 297-317, 1994. http:// dx.doi.org/10.1177/0893318994007003004

VAARA, E.; SORSA, V.; PALLI, P. On the force potential of strategy texts: a critical discourse analysis of a strategic plan and its power effects in a city organization. Organization, v. 17, n. 6, p. 685-702, 2010. http:// dx.doi.org/10.1177/1350508410367326

VAUGHAN, D. W. The Dark Side of Organizations: Mistake, Misconduct and Disaster. Annual Review of Sociology, v. 25, p. 271-305, 1999. http://dx.doi. org/10.1146/annurev.soc.25.1.271
VENDELO, M. T. Narrating corporate reputation. International Studies of Management \& Organization, v. 28 , n. 3, p. $120-137,1998$.

WALTERS, R. Bhopal. Corporate Crime and Harms on the Powerfull. Global Social Policy, v. 9, p. 324-327, 2009. http://dx.doi.org/10.1177/14680181090090030205

WEICK, K. E. Enacted Sensemaking in Crisis Situations. Journal of Management Studies, v. 25, n. 4, p. 305-317, 1988. http://dx.doi.org/10.1111/j.1467-6486.1988.tb00039.x

WHITTINGTON, R. Teorias sobre estratégia. In: WHITTINGTON, R. O que é estratégia. São Paulo: Pioneira Thomson Learning, 2002. cap. 2. 
